\title{
Pelanggaran Maksim Kesantunan Dalam Novel Nijuushi No Hitomi Karya Sakae Tsuboi
}

\author{
I Nengah Ariana ${ }^{1 *}$, Ngurah Indra Pradhana ${ }^{2}$, Ni Luh Kade Yuliani Giri ${ }^{3}$ \\ ${ }^{[123]}$ Program Studi Sastra Jepang Fakultas Ilmu Budaya \\ [ari.ananda@live.com] ${ }^{2}$ [indra.pradana@unud.ac.id] ${ }^{3}$ [giri222000@yahoo.com] \\ *Corresponding Author
}

\begin{abstract}
Abstrak
Penelitian ini berjudul "Pelanggaran Maksim Kesantunan dalam Novel Nijuushi no Hitomi karya Sakae Tsuboi". Tujuan penelitian ini adalah untuk mengetahui jenis tindak tutur ilokusi dan bentuk pelanggaran maksim kesantunan dalam Novel Nijuushi no Hitomi karya Sakae Tsuboi. Penelitian ini menggunakan metode simak dan teknik catat. Teori yang digunakan adalah teori tindak tutur yang dikemukakan oleh Searle (1969) dan teori prinsip kesantunan yang dikemukakan oleh Leech (1983). Hasil penelitian menunjukkan bahwa dalam novel nijuushi no hitomi karya Sakae Tsuboi terdapat pelanggaran terhadap maksim kesantunan yaitu (1) maksim kebijaksanaan (enam buah data yang bertujuan memohon, memerintah, melarang, mengajak dan membujuk), (2) maksim kedermawanan (satu buah data yang bertujuan mengejek), (3) maksim penghargaan (delapan buah data yang bertujuan mengejek, menyalahkan dan memberi nama), (4) maksim permufakatan (empat data yang bertujuan berbohong, menasehati, berpasrah dan memecat) dua (5) maksim simpati (dua data yang bertujuan memerintah dan mengejek.
\end{abstract}

Kata kunci : pragmatik, tindak tutur ilokusi, prinsip kesantunan.

\begin{abstract}
This research entitled "Violation of politeness maxim in Nijuushi no Hitomi's Novel by Sakae Tsuboi". This research aims to find out the kind speech act and type of violated conversation which got violated in Nijuushi no Hitomi's Novel by Sakae Tsuboi. The data analyzed using descriptive method. The theories used for analyzing are speech acts (illocutionary acts) theory by Searle (1969) and the politeness principle theory by Leech (1983). Based on the analysis that has been done, there are violation of politeness maxim, such as (1) tact maxim (six data that aims for requesting, commanding, prohibiting, inviting and persuading), (2) generosity maxim (one data that aims for mocking), (3) approbation maxim (eight data that aims for mocking, blaming and naming) (4) agreement maxim (four data that aims for lying, advising, resigning and dismissing) (5) sympathy maxim (two data that aims for commanding and mocking).
\end{abstract}

Keywords: pragmatic, illocutionary act, politeness principle

\section{Latar Belakang}

Kegiatan berkomunikasi dapat berlangsung secara efektif dan efisien apabila penutur dan mitra tutur saling memahami isi tuturan dalam berkomunikasi. Pragmatik adalah studi tentang makna yang disampaikan oleh penutur (atau penulis) dan ditafsirkan oleh mitra tutur (atau pembaca). Menurut Leech (1983:8) pragmatik adalah studi tentang makna dalam hubungannya dengan situasi ujar (speech situation). Situasi ujar seperti keadaan lingkungan akan mempengaruhi kegiatan bertutur antara penutur dan mitra tutur. Selain itu, tuturan bergantung dengan siapa lawan 
tutur, jenis kelamin, pendidikan, latar belakang sosial dan budaya. Dalam situasi seperti apapun penutur dan mitra tutur diharapkan dapat melakukan komunikasi secara kooperatif agar tuturan dapat tersampaikan kepada peserta tutur.

Untuk menunjang komunikasi supaya dapat tersampaikan dan dimengerti oleh mitra tutur, Searle di dalam bukunya Speech Acts: An Essay in The Philosophy of Language (1969, 2324) mengemukakan bahwa secara pragmatis setidak-tidaknya ada tiga jenis tindakan yang dapat diwujudkan oleh seorang penutur, yakni tindak lokusi (locutionary act), tindak ilokusi (illocutionary act), dan tindak perlokusi (perlocutionary act). Tindak tutur itu dipakai acuan dalam berkomunikasi sehingga maksud tuturan-tuturan yang disampaikan penutur dapat dimengerti oleh mitra tutur.

Penutur dalam menyampaikan maksud tuturannya terkadang muncul pelanggaran maksim kesantunan. Menurut Leech ada enam maksim dalam maksim kesantunan yakni maksim kebijaksanaan, maksim kedermawanan, maksim penghargaan, maksim kesederhanaan, maksim permufakatan, dan maksim simpati (Rahardi, 2005:5966). Apabila salah satu peserta tutur tidak mengerti maksud tuturan maka akan terjadi penyimpangan yang berakibat pertuturan tidak berjalan lancar.

Berdasarkan latar belakang tersebut novel Nijuushi no Hitomi karya Sakae Tsuboi menarik untuk diteliti karena ditemukan data tindak tutur yang melanggar maksim dalam prinsip kesantuanan. Data tindak tutur yang melanggar maksim dalam prinsip kesantunan dalam novel ini sangat mencukupi untuk digunakan sebagai bahan penelitian.

\section{Pokok Permasalahan}

Rumusan masalah dalam penelitian ini adalah sebagai berikut:

a) Bagaimanakah jenis tindak tutur ilokusi yang melanggar maksim kesantunan dalam novel Nijuushi no Hitomi karya Sakae Tsuboi?

b) Bagaimanakah bentuk pelanggaran maksim kesantunan dalam novel Nijuushi no Hitomi karya Sakae Tsuboi?

\section{Tujuan Penelitian}

Tujuan dari penelitian ini adalah untuk mengetahui jenis tindak tutur yang melanggar maksim dalam prinsip kesantunan dalam novel Nijuushi no Hitomi karya Sakae Tsuboi (1952). Selain itu juga untuk mengetahui bentuk pelanggaran maksim dalam prinsip kesantunan yang ada dalam novel ini.

\section{Metode Penelitian}

Pada penelitian ini data dikumpulkan dengan menggunakan metode simak dan teknik catat. Pada tahap analisis data digunakan metode deskriptif, ini dilakukan dengan cara mendeskripsikan fakta-fakta, yaitu tindak tutur yang melanggar maksim yang terdapat dalam novel kemudian disusul dengan analisis data. Penyajian hasil analisis data pada penelitian ini menggunakan metode informal. Metode penyajian informal adalah perumusan dengan kata-kata biasa (Sudaryanto, 1993; 145). Teori yang digunakan untuk menganalisisnya menggunakan teori tindak tutur yang dikemukakan oleh Searle dan teori prinsip kesantunan yang dikemukakan oleh Leech.

\section{Hasil dan Pembahasan}

Pertuturan dapat tersampaikan antara penutur dan mitra tutur perlu mempertimbangkan prinsip. Prinsip kesantunan menurut Leech (1983) meliputi enam maksim yakni maksim 
kebijaksanaan, maksim kedermawanan, maksim penghargaan, maksim kesederhanaan, maksim permufakatan, dan maksim simpati. Searle (1969) dalam bukunya Speech Act: An Essay in The Philosophy of Language menyatakan bahwa dalam praktik penggunaan bahasa terdapat setidaknya tiga macam tindak tutur, salah satunya adalah tindak tutur ilokusi. Searle membagi tindak tutur ilokusi menjadi lima macam bentuk tuturan yakni asertif, direktif, ekspresif, komisif, dan deklarasi. Dari kelima bentuk tuturan terdapat empat jenis tindak tutur ilokusi dalam novel Nijuushi no Hitomi karya Sakae Tsuboi. Tindak tutur dalam novel digunakan untuk mengetahui pelanggaran maksim yang terjadi. Berikut adalah data dalam novel mengenai salah satu tuturan yang terjadi:

\subsection{Pelanggaran Kebijaksanaan}

Maksim

$$
\begin{aligned}
& \text { 大工さん : あ、これはこ } \\
& \text { れは先生、先生まで手つだい } \\
& \text { にきておくれたんかな。そん } \\
& \text { ならひとつ、その大ぜいの弟 } \\
& \text { 子を使うて道路の石でも浜べ } \\
& \text { ころがしてつかあさらん（ }
\end{aligned}
$$
ださいませんか）。ここは大 エでないと都会がわるいです わい。それとも、手斧でも持 ちますかな。

大石先生：ね、みんなで、 これから道路の砂利掃除をし ようか。

生徒：うん、うん。

しよう、しよう。

\begin{abstract}
Taiku san : A, kore wa kore wa sensei, sensei made tetsudai ni kite okuretankana. Sonnara hitotsu, sono oozei no deshi o tsukaute douro no ishi demo hamabe koro ga shite tsukaasaran (kudasaimasenka). bSore to mo, chouna de mo mochimasukana.
\end{abstract}

Oishi Sensei : Ne, minna de, kore kara douro no jari souji o shiyouka.

Murid :Un, un. Shiyou, shiyou.

(二十四の瞳, 37)

Tukang kayu : “Oh, Kaukah itu, Ibu Guru? Apa kau datang kemari untuk membantu kami juga? Kalau begitu, bisakah kau menyuruh anak-anak itu menyingkirkan batu-batu dari jalanan ke pantai? Biar tukang kayu seperti aku saja yang membereskan urusan di sini. Atau kau mau memakai kapak?"

Ibu Guru Oishi : "Bagaimana kalau kita semua menyingkirkan batu-batu dari jalan?"

Murid : "Bagus! Ayo!"

(Dua Belas Pasang Mata, 46)

Tuturan (1) terjadi antara Ibu Guru Oishi dengan Tukang Kayu saat Ia berkeliling untuk menanyakan kabar keluarga-keluarga yang mendapat musibah. Si Tukang Kayu yang ikut membantu-bantu bertutur kepada Ibu Guru Oishi 'Sonnara hitotsu, sono oozei no deshi o tsukaute douro no ishi demo hamabe koro ga shite tsukaasaran (kudasaimasenka)' yang terjemahannya 'Kalau begitu, bisakah kau menyuruh anak-anak itu menyingkirkan batubatu dari jalanan ke pantai?' 
merupakan tuturan yang melanggar maksim kebijaksanaan yang bermakna memohon. Pelanggaran maksim terjadi karena $\mathrm{Si}$ Tukang Kayu memohon kepada Ibu Guru Oishi untuk menyuruh anak-anak menyingkirkan batu-batu dari jalanan. Dilihat dari pola kalimat $\sim t e$ kudasaimasenka dalam kalimat sonnara hitotsu, sono oozei no deshi o tsukaute douro no ishi demo hamabe koro ga shite tsukaasaran (kudasaimasenka) merupakan bentuk memohon sopan. Menurut Makino dan Tsutsui (1989:210) pola kalimat te kudasaimasenka merupakan bentuk pertanyaan negatif yang membuat sebuah perintah lebih sopan. Tukang Kayu memohon Ibu Guru Oishi dengan menggunakan tuturan di atas karena adanya status sosial antara Tukang Kayu dan Ibu Guru Osihi. Tujuan dari tuturannya agar anak-anak mau mendengarkan dan melaksanakan apa yang diucapkan oleh Ibu Guru mereka.

\subsection{Pelanggaran Maksim Kedermawanan}

$$
\begin{aligned}
& \text { 早苗 : な先生、そう } \\
& \text { 思いませんか。こういうとこ } \\
& \text { ろ出るとーばん役に立たんの } \\
& \text { は学校の先生だと。 } \\
& \text { ミサ子 : わたしこそ。 } \\
& \text { マスノ：さあ、ソンキ、 }
\end{aligned}
$$

あんまになるおまえのために、 も一ぱいいこう。

大石先生：ソンキさん、

みんな行儀わるいのよ。あん

たももっとらくにすわったら。

$$
\begin{aligned}
& \text { 磯吉 : いやあ先生、 } \\
& \text { このほうがじつは、らくなん } \\
& \text { です。 }
\end{aligned}
$$

Sanae : Na sensei, sou omoimasen ka. Kou iu tokoro deru to ichiban yaku ni tatan no wa gakkou no sensei da to.

Misako : Watashi.

Masuno : Saa, Sonki, anma ni naru omae no tame ni, mo ippai ikou.

Oishi Sensei : Sonki san, minna gyougi warui no yo.Anta mo motto raku ni suwattara.

Isokichi : Iyaa sensei, kono hou ga jitsu wa, rakunan desu.

(二十四の瞳, $239-240$ )

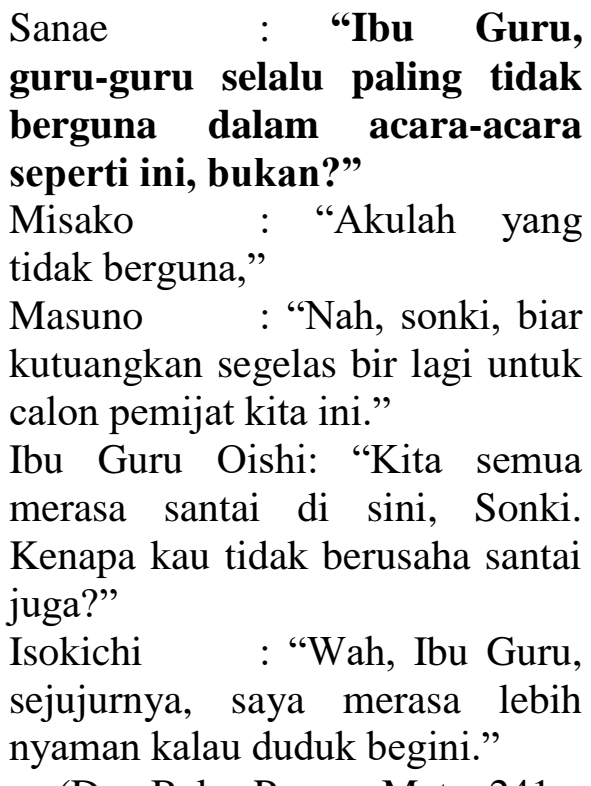
(Dua Belas Pasang Mata, 241 -

Tuturan (2) terjadi antara Sanae, Masuno, Ibu Guru Oishi dan Isokichi saat pesta jamuan di sebuah restoran. Para mantan murid Ibu Guru Oishi sibuk dengan tugasnya masing-masing terkecuali Misako dan Isokichi yang duduk saja karena buta. Tuturan yang disampaikan Sanae 'Na sensei, sou 
omoimasen ka. Kou iu tokoro deru to ichiban yaku ni tatan no wa gakkou no sensei da to' yang terjemahannya 'Ibu Guru Oishi, guru-guru selalu paling tidak berguna dalam acara-acara seperti ini, bukan?' merupakan tuturan yang melanggar maksim kedermawanan yang bermakna mengejek. Pelanggaran maksim terjadi karena Sanae menuturkan gurunya tidak berguna dalam acara tersebut. Sanae seharusnya menyampaikan tuturan 'biarkan kami yang mengerjakan acara ini, Ibu Guru Oishi bisa bersantai karena pesta ini dutujukan untukmu' agar terdengar lebih hormat. Tujuan Sanae menuturkan tuturan tersebut kepada Ibu Guru Oishi adalah untuk bercanda dan membuat suasana menjadi santai.

\subsection{Pelanggaran Maksim Penghargaan}

おかみさん：おなご先生、

あんたいま、なにがおかしい

てわらうたんですか？

おかみさん：人が災難に会 うたのが、そんなおかしいで すか。うちのお父さんは屋根 から落ちましたが、それもお かしいでしょう。みんごと大 した怪我は、しませなんだけ んど、大怪我でもしたら、な お、おかしいでしょう。 大石先生：すみません。 そんなつもりはちょつとも一。 おかみさん：いいえ、そん ならんで人の災難を笑うたん です。おていさいに、道掃除 などしてもらいますまい。と
にかく、わたしの家の前はほ つといてもらいます。なんじ や、じぶんの自動車が走れん からやってるんじやないか、 あほくさい。そんなら、じぶ んだけでやりやあよい。

Okamisan : Onago sensei antaima, nani ga okashiite ite warautandesuka?

Okamisan : Hito no sainan ni outa no ga, sonna okashi desuka. Uchi no otousan wa yane kara ochimashita ga, sore mo okashii deshou. Mingoto taishita kega wa, shimasenan dakendo, ookega de mo shitara, nao, okashii deshou.

Oishi Sensei : Sumimasen. Sonna tsumori wa chotto mo--.

Okamisan : Iie, sonnaran de hito no sainan o warautan desu. Oteisai ni, Michisouji na doshite moraimasumai. Tonikaku, watashi no ie no mae wa hotto ite miraimasu. Nanja, jibun no jidousha ga hashiren kara yatterun ja nai ka, ahokusai. Sonnara, jibun dake de yaryaa yoi.

(三十四の瞳, 40

Pemilik toko : "Ibu Guru, kau menertawakan apa tadi?"

Pemilik toko : "Apa kemalangan orang-orang lain kau anggap lucu? Suamiku jatuh dari atap, tapi itu mungkin juga lucu, ya? Sayang sekali lukanya tidak begitu 
parah. Kalau iya, tentunya bakal lebih lucu lagi, kan?"

Ibu Guru Oishi : "Maafkan saya. Saya tidak bermaksud..."

Pemilik toko : "Sudahlah.

Kalau begitu kenapa kau menertawakan nasib malang orang-orang lain? Tidak usah membersikan jalan kalau cuma untuk mencari muka! Pokoknya, biarkan saja jalanan di depan rumahku apa adanya. Huh-dia bersih-bersih supaya bisa mengendarai sepedanya. Dasar konyol! Kalau begitu, lebih baik dia bersihkan saja sendiri."

(Dua Belas Pasang Mata, 49)

Tuturan (3) terjadi antara Pemilik Toko dan Ibu Guru Oishi saat Ibu Guru Oishi beserta murid-murid sedang membantu membersihkan batu-batu akibat badai semalam. Ibu Guru Oishi tidak dapat menahan tawanya karena mendengar cerita dan gaya muridnya. Tuturan Si pemilik toko kelontong 'Hito no sainan ni outa no ga, sonna okashidesuka. Uchi no otousan wa yane kara ochimashita ga, sore mo okashii deshou. Mingoto taishita kega wa, shimasenan dakendo, ookega de mo shitara, nao, okashii deshou' yang terjemahannya 'Apa kemalangan orang-orang lain kau anggap lucu? Suamiku jatuh dari atap, tapi itu mungkin juga lucu, ya? Sayang sekali lukanya tidak begitu parah. Kalau iya, tentunya bakal lebih lucu lagi, kan?' merupankan tuturan yang melanggar maksim penghargaan yang bermakna menyalahkan. Pelanggaran maksim terjadi karena Pemilik Toko tidak terima ditertawakan akibat musibah yang dialaminya, padahal Ibu Guru Oishi menertawakan cerita dan gaya muridnya. Tujuan tuturan yang disampaikan oleh
Pemilik Toko supaya Ibu Guru Oishi berhenti tertawa.

\subsection{Pelanggaran Maksim}

Permufakatan

生徒

：先生、

こんどくる先生は？

小林先生 ：さあ、

もうそろそろ見えるでしょう。 生徒：こんど

の先生、どんな先生?

小林先生 : しらん

のよ、まだ。

生徒

：また女

学校出え出え?

小林先生：さあ、

ほんとにしらんの。

でもみんな、性わるしたら、

だめよ。

Seito : Sensei,

kondo kuru sensei ha?

Kobayashi Sensei :Saa, mou soro soro mieru deshou.

Seito

Kondo

no sensei, donna sensei?

Kobayashi Sensei : Shiran no yo, mada.

Seito

Mata

sogakkou dee dee?

Kobayashi Sensei : Saa, honto ni shiran no. Demo minna, shouwaru shitara, dame yo.

(二十四の瞳 6 - 
Murid : "Ibu

Guru Kobayashi, dimana guru baru itu?"

Ibu Guru Kobayashi : "Kurasa dia tak lama lagi akan datang."

Murid : "Seperti apa dia?"

Ibu Guru Kobayashi : "Aku belum tahu."

Murid : "Baru

lulusan SMA lagi?"

Ibu Guru Kobayashi : “Aku

benar-benar tidak tahu. Pokoknya, kalian jangan jahat padanya."

(Dua Belas Pasang Mata, 17)

Tuturan (4) terjadi antara Ibu Guru Kobayashi dan murid-murid saat perjalanan pulang dari upacara penutupan di sekolah utama. Dia berpamitan kepada murid-murid sambil membagikan sekotak karamel ke mereka. Berbagai pertanyaan muncul dari para murid tentang guru baru yang akan menggantikan Ibu Guru Kobayashi. Tuturan yang disampaikan oleh Ibu Guru Kobayashi 'Saa, honto ni shiran no.' yang terjemahannya 'Aku benar-benar tidak tahu' merupakan tuturan yang melanggar maksim permufakatan yang bermakna berbohong. Pelanggaran maksim terjadi karena Ibu Guru Kobayashi tidak ingin menceritakan tentang guru baru yang akan mengajar mereka nanti, padahal Ia sudah bertemu dengan guru baru dan menceritakan tentang kelakuan para murid. Tujuan tuturan yang disampaikannya supaya murid-murid tidak nakal terhadap guru baru seperti yang mereka lakukan kepadanya dulu.

\subsection{Pelanggaran Maksim Simpati}

$$
\text { ミサ子 : ソンキさんの }
$$

ことは？生きてもどっても、

めくらではこまりますわ。い

つそ死ぬばよかつたのに。

大石先生：そんなこと、

ミサ子さん、そんなことどう

していえるの。せっかく立ち

あがろうとしているのに。こ

とにあなたは同級生よ。

Misako : Sonki san no koto wa? Ikitemodottemo, mekura de wa komarimasu wa. Isso shinuba yokatta noni.

Oishi Sensei : Sonna koto, Misako san, sonna koto doushite ieru no. Sekkaku tachi agarou toshite iru noni. Koto ni anata doukyuusei yo.

(二十四の瞳,

$221-222)$

Misako : "Anda sudah dengar tentang Sonki? Dia pulang dalam keadaan hidup, tapi apa yang bisa dia lakukan sebagai orang buta? Mungkin akan lebih baik seandainya waktu itu dia tewas."

Ibu Guru Sensei : "Bagaimana mungkin kau tega bicara seperti itu, Misako, padahal dia sedang berusaha memulai hidupnya dari awal lagi? Apalagi kau dulu teman sekelasnya."

(Dua Belas Pasang Mata, 224 226)

Tuturan (5) terjadi antara Ibu Guru Oishi dengan Misako mantan muridnya saat ke sekolah menjemput anaknya 
melewati pantai. Misako menceritakan bahwa yang masih tersisa temantemannya ada dua laki-laki dan tiga perempuan. Salah satu yang dia ceritakan adalah tentang Isokichi. Tuturan yang disampaikan Misako tentang Isokichi 'Ikitemodottemo, mekura de wa komarimasu wa. Isso shinuba yokatta noni' yang terjemahannya 'Dia pulang dalam keadaan hidup, tapi apa yang bisa dia lakukan sebagai orang buta? Mungkin akan lebih baik seandainya waktu itu dia tewas' merupakan tuturan yang melanggar maksim simpati yang bermakna mengejek. Misako menuturkan keadaan Sonki setelah kembali dari medan perang bahwa dia masih hidup, tetapi dia pulang dengan keadaan cacat. Pelanggaran maksim terjadi karena Misako sebagai teman dari Isokichi seharusnya memaksimalkan sikap simpati terhadap keadaan Isokichi.

\section{Simpulan}

Berdasarkan hasil penelitian mengenai pelanggaran maksim kesantunan dalam novel Nijuushi No Hitomi karya Sakae Tsuboi, dapat disimpulkan beberapa hal sesuai dengan permasalahan yang dibahas pada pebelitian ini. Simpulan pada penelitian ini adalah (1) maksim kebijaksanaan (enam buah data yang bertujuan memohon, memerintah, melarang, mengajak dan membujuk), (2) maksim kedermawanan (satu buah data yang bertujuan mengejek), (3) maksim penghargaan (delapan buah data yang bertujuan mengejek, menyalahkan dan memberi nama), (4) maksim permufakatan (empat data yang bertujuan berbohong, menasehati, berpasrah dan memecat) dua (5) maksim simpati (dua data yang bertujuan memerintah dan mengejek.

\section{Daftar Pustaka .}

Leech, Geoffrey. 1983. Prinsip - Prinsip Pragmatik. Jakarta: Universitas Indonesia.

Matsuura, Kenji. 1994. Nihongo Indonesiago Jiten. Kyoto: Kyoto Sangyo Univ. Press.

Rahardi, K. 2005. Pragmatik: Kesantunan Imperatif Bahasa Indonesia. Jakarta: Erlangga.

Searle, John R. 1969. Speech Acts, An Essay in the Philosophy of Language. Cambridge: Cambridge University Press.

Sudaryanto. 1993. Metode dan Aneka Teknik Analisis Bahasa: Pengantar Penelitian Wahana Kebudayaan Secara Ligustis. Yogyakarta: Duta Wacana University Press.

Tsuboi, Sakae. 1952. Nijuushi no Hitomi. Tokyo: Kobunsha Co., Ltd. 